\title{
A comparative study to evaluate endometrial aspiration using Karman's cannula versus dilatation and curettage in cases of abnormal uterine bleeding
}

\section{Neetu Sangwan Tomar ${ }^{1 *}$, Seerat Sandhu ${ }^{1}$, Supriya Mahipal ${ }^{1}$, Abhimanyu Chaudhary ${ }^{2}$}

\author{
${ }^{1}$ Department of Obstetrics and Gynecology, PGIMS, Rohtak, Haryana, India \\ ${ }^{2}$ Department of Radiodiagnosis, MGM Medical College, Kamothe, Navi Mumbai, Maharashtra, India
}

Received: 09 January 2020

Accepted: 07 February 2020

\section{*Correspondence:}

Dr. Neetu Sangwan Tomar,

E-mail: drneetutomar_in@yahoo.co.in

Copyright: ( ) the author(s), publisher and licensee Medip Academy. This is an open-access article distributed under the terms of the Creative Commons Attribution Non-Commercial License, which permits unrestricted non-commercial use, distribution, and reproduction in any medium, provided the original work is properly cited.

\section{ABSTRACT}

Background: Abnormal uterine bleeding (AUB) is defined as any variation from the normal menstrual cycle such as changes in regularity, frequency, duration of flow or amount of flow. Objective of this study was to compare the adequacy and diagnostic accuracy of endometrial aspiration using Karman's cannula versus dilatation and curettage in women with abnormal uterine bleeding.

Methods: This prospective study was conducted on 250 women with AUB in age group of more than 40 years. In all patients, endometrial aspiration was done with manual vacuum aspiration (MVA) syringe attached to 4 mm Karman's cannula without anesthesia. The sample was collected in a bottle containing formalin and was labelled as sample A. After that, intracervical local anesthesia (1\% Xylocaine) was given and cervix was dilated and scrapping of endometrial lining with sharp curette was done. The sample was also collected in a bottle containing formalin and was labelled as sample B. Both the samples A and B were sent for histopathology. The histopathology report of aspiration was compared with that of dilatation and curettage sample.

Results: Endometrial aspiration biopsy had sensitivity of $92.3 \%$, specificity of $100 \%$, positive predictive value of $100 \%$ and negative predictive value of $99.56 \%$ for diagnosis of endometrial pathology while considering D and C gold standard. The sample adequacy of endometrial aspiration was $98.8 \%$ as compared to dilatation and curettage $(98 \%)$.

Conclusions: Present study showed that endometrial aspiration biopsy is an alternate to traditional dilatation and curettage in diagnosing endometrial pathologies in women with abnormal uterine bleeding.

Keywords: Abnormal uterine bleeding, Accuracy, Drug and cosmetic, Endometrial aspiration

\section{INTRODUCTION}

Abnormal uterine bleeding (AUB) is defined as any variation from the normal menstrual cycle such as changes in regularity, frequency, duration of flow or amount of flow. ${ }^{1}$ It occurs in $9-14 \%$ of women between menarche to menopause, significantly impacting quality of life and imposing financial burden. ${ }^{2-4}$ Endometrial biopsy is an important step in the assessment of abnormal uterine bleeding to rule out endometrial carcinoma so that medical or conservative surgery can be offered and unnecessary radical surgery can be avoided. Hence, present study was planned to evaluate and compare the adequacy and diagnostic accuracy of endometrial aspiration with conventional dilatation and curettage in cases of abnormal uterine bleeding.

\section{METHODS}

This prospective, randomized study was conducted on 250 women of more than 40 years of age with abnormal uterine bleeding who presented in the outpatient department of 
obstetrics and gynecology, Pt B D Sharma Post Graduate Institute of Medical sciences, Rohtak (Table 1).

Table 1: Baseline characteristics of patients.

\begin{tabular}{|ll|}
\hline $\begin{array}{l}\text { Age range (years) } \\
\text { Mean } \pm \text { SD }\end{array}$ & $\mathbf{5 0 . 7 9 \pm 9 . 5 8}$ \\
\hline Range & $40-84$ \\
\hline SE status & LM - 166 (66.4\%) \\
\hline Parity & UM - 84 (33.6\%) \\
\hline P1 & $2(0.8 \%)$ \\
\hline P2 & $96(38.4 \%)$ \\
\hline$>$ P3 & $152(60.8 \%)$ \\
\hline Literacy & Illiterate - 106 (42.4\%) \\
\hline Literate - 144 (57.6\%) \\
\hline Occupation & Housewife - 221 (88.4\%) \\
\hline $\begin{array}{l}\text { Duration of illness } \\
\text { (months) (Mean } \pm \text { SD) }\end{array}$ & Unemployed - 29 (11.6\%) \\
\hline
\end{tabular}

Patients with suspected pelvic infection, pre-malignant and malignant lesions of cervix, cervical stenosis, uterine polyp, pregnancy and related causes of bleeding like abortion and molar pregnancy, coagulopathy, uncontrolled severe hypertension and uncontrolled diabetes, heart diseases, profusely bleeding patients requiring therapeutic curettage, women on oral contraceptives and with IUCD in situ were excluded from the study.

Written informed consent was taken from all patients included in the study. A detailed menstrual history was taken followed by general physical and systemic examination. Per speculum and bi-manual vaginal examination was done to rule out any local causes of bleeding. Laboratory tests including hemoglobin, coagulation profile, thyroid profile and ultrasound pelvis was done.

In all patients, endometrial aspiration was done with manual vacuum aspiration (MVA) syringe attached to 4 $\mathrm{mm}$ Karman's cannula without anesthesia. The sample was collected in a bottle containing formalin and was labelled as sample A. After that, intracervical local anesthesia (1\% Xylocaine) was given and cervix was dilated and scrapping of endometrial lining with sharp curette was done. The sample was also collected in a bottle containing formalin and was labelled as sample B. Both the samples A and B were sent for histopathology. The histopathology report of aspiration was compared with that of dilatation and curettage sample.

\section{Outcome}

The primary outcome was determined by sensitivity and specificity for diagnosis of endometrial pathology using aspiration biopsy.

Secondary outcome was evaluated by acceptability and user satisfaction.

\section{Compliance with ethical standards}

All procedures performed in studies involving human participants were in accordance with the ethical standards of the institutional and/or national research committee and with the 1964 Helsinki declaration and its later amendments or comparable ethical standards.

\section{Statistical analysis}

The collected data was analyzed with the help of Statistical Package for Social Sciences (SPSS) version 20.0. frequency distribution and cross-tabulation was used to create summary and compare results within and across various categories using appropriate statistical test.

\section{RESULTS}

Two fifty women with eligible criteria were recruited in the study. All the patients underwent endometrial sampling by both methods. The histopathology report of samples obtained by endometrial aspiration versus dilatation and curettage were compared (Table 2).

Table 2: Comparison of histopathological diagnosis following endometrial aspiration biopsy versus dilatation and curettage (D and $\mathrm{C}$ ).

\begin{tabular}{|lll|}
\hline Findings & $\begin{array}{l}\text { Endometrial } \\
\text { sampling }\end{array}$ & D and C \\
\hline Proliferative & $120(48 \%)$ & $119(47.6 \%)$ \\
\hline Secretory & $115(46 \%)$ & $111(44.4 \%)$ \\
\hline Senile cystic atrophy & 0 & $2(0.8 \%)$ \\
\hline $\begin{array}{l}\text { Endometrial hyperplasia } \\
\text { without atypia }\end{array}$ & $2(0.8 \%)$ & $3(1.2 \%)$ \\
\hline $\begin{array}{l}\text { Endometrial hyperplasia } \\
\text { with atypia }\end{array}$ & $5(2 \%)$ & $5(2 \%)$ \\
\hline Carcinoma & $5(2 \%)$ & $5(2 \%)$ \\
\hline Inadequate sample & $3(1.2 \%)$ & $5(2 \%)$ \\
\hline Total & $\mathbf{2 5 0}$ & $\mathbf{2 5 0}$ \\
\hline
\end{tabular}

In this study we have considered dilatation and curettage as gold standard. Hence when compared to dilatation and curettage, the sensitivity of endometrial aspiration is $92.3 \%$, specificity is $100 \%$, positive predictive value is $100 \%$ and negative predictive value is $99.56 \%$ (Table 3 ).

Table 3: Categorization of histopathological findings following endometrial aspiration biopsy and dilatation and curettage (D and $\mathrm{C}$ ).

\begin{tabular}{|lll|}
\hline $\begin{array}{l}\text { Endometrial } \\
\text { aspiration biopsy }\end{array}$ & \multicolumn{2}{l|}{ Dilatation and Curettage } \\
\hline Abnormal & $12(\mathrm{a})$ & 0 (b) \\
\hline Normal & 1 (C) & $230(\mathrm{~d})$ \\
\hline
\end{tabular}

For diagnosis of endometrial hyperplasia, the sensitivity of endometrial aspiration is $87.5 \%$, specificity is $100 \%$, 
positive predictive value is $100 \%$ and negative predictive value is $99.57 \%(\mathrm{p}<0.001$, Table 4$)$.

\section{Table 4: Comparison of endometrial aspiration biopsy versus $D$ and $C$ in patients of endometrial hyperplasia.}

\begin{tabular}{|lll|}
\hline Procedure & Positive/total & Percentage \\
\hline $\begin{array}{l}\text { Endometrial } \\
\text { aspiration biopsy }\end{array}$ & $7 / 8$ & 87.5 \\
\hline $\begin{array}{l}\text { Dilatation and } \\
\text { curettage }\end{array}$ & $8 / 8$ & 100 \\
\hline
\end{tabular}

While diagnosing carcinoma by using endometrial aspiration, sensitivity is $100 \%$, specificity is $100 \%$, positive predictive value is $100 \%$ and negative predictive value is $100 \%$ (Table 5).

Table 5: Comparison of endometrial aspiration biopsy versus $D$ and $C$ in patients of endometrial carcinoma.

\begin{tabular}{|lll|}
\hline Procedure & Positive/total & Percentage \\
\hline $\begin{array}{l}\text { Endometrial } \\
\text { aspiration biopsy }\end{array}$ & $5 / 5$ & 100 \\
\hline $\begin{array}{l}\text { Dilatation and } \\
\text { curettage }\end{array}$ & $5 / 5$ & 100 \\
\hline
\end{tabular}

In this study, tissue adequacy in samples collected by endometrial aspiration was $98.8 \%$ whereas in samples collected by dilatation and curettage it was $98 \%$ $(\mathrm{p}<0.001$, Table 6).

Table 6: Comparison of sample adequacy of endometrial aspiration biopsy versus dilatation and curettage.

\begin{tabular}{|lll|}
\hline Procedure & Adequate & Inadequate \\
\hline $\begin{array}{l}\text { Endometrial } \\
\text { aspiration biopsy }\end{array}$ & $247(98.8 \%)$ & $3(1.2 \%)$ \\
\hline $\begin{array}{l}\text { Dilatation and } \\
\text { Curettage }\end{array}$ & $245(98 \%)$ & $5(2 \%)$ \\
\hline
\end{tabular}

Hence it is an alternate to traditional dilatation and curettage in diagnosing endometrial pathologies in women with abnormal uterine bleeding.

In 1 patient, endometrial aspiration showed proliferative endometrium but endometrial hyperplasia without atypia in dilatation and curettage. In 4 patient, endometrial aspiration showed secretory endometrium but inadequate sample in dilatation and curettage. In 1 patient, inadequate sample was there in both methods. In 2 patients, endometrial aspiration showed inadequate sample but D and C showed senile cystic atrophy.

\section{DISCUSSION}

The main aim is to evaluate and compare the adequacy and diagnostic accuracy of endometrial aspiration with conventional dilatation and curettage in cases of abnormal uterine bleeding.

In this study authors have considered dilatation and curettage as gold standard. Hence when compared to dilatation and curettage, the sensitivity of endometrial aspiration is $92.3 \%$, specificity is $100 \%$, positive predictive value is $100 \%$ and negative predictive value is $99.56 \%$. The results were in concordance with the study conducted by Rachamallu et al, in which endometrial aspiration had sensitivity of $93.4 \%$, specificity of $100 \%$, positive predictive value of $100 \%$ and negative predictive value of $92.3 \% .^{5}$ In study done by Yasmin et al, sensitivity, specificity, PPV and NPV were 100\%, $84 \%$, $100 \%$ and $95 \%$ respectively. ${ }^{6}$

For diagnosis of endometrial hyperplasia, the sensitivity of endometrial aspiration is $87.5 \%$, specificity is $100 \%$, positive predictive value is $100 \%$ and negative predictive value is $99.57 \%(\mathrm{p}<0.001)$. While diagnosing carcinoma by using endometrial aspiration, sensitivity is $100 \%$, specificity is $100 \%$, positive predictive value is $100 \%$ and negative predictive value is $100 \%$.

In study conducted by Machado et al, in 1535 patients, it was concluded that endometrial aspiration was $84.2 \%$ sensitive, $99.1 \%$ specific, $96.9 \%$ accurate with $94.1 \%$ positive predictive value and $93.7 \%$ negative predictive value for diagnosing endometrial hyperplasia and carcinoma. $^{7}$

Three hundred sixty endometrial cancer patients had preoperative endometrial sampling to evaluate the ability of preoperative endometrial sampling to accurately diagnose high grade endometrial cancer were included in Gloria et al, study. Gloria et al, concluded that endometrial aspiration biopsy was $93.8 \%$ sensitive for diagnosing low grade endometrial cancer and it was 99.2\% sensitive for diagnosing high grade endometrial cancer. They also concluded that the endometrial sampling by aspiration is sensitive and accurate for the diagnosis of high-grade endometrial tumors. ${ }^{8}$

In this study, tissue adequacy in samples collected by endometrial aspiration was $98.8 \%$ whereas in samples collected by dilatation and curettage it was $98 \%$ ( $\mathrm{p}<$ 0.001). In one study conducted by Patil et al, it was found that tissue adequacy is similar i.e. $96 \%$ in both samples. ${ }^{9}$

Baral and Pudasini reported adequacy of $92 \%$ in endometrial aspiration while conducting a study on patients of abnormal uterine bleeding. ${ }^{10}$ In a study conducted by Jairajpuri et al, it was concluded that endometrial aspiration has adequacy of $97.4 \%{ }^{11}$ Shams et al, also showed $98 \%$ adequacy of endometrial aspiration while taking endometrial biopsy. ${ }^{12}$

Singh $\mathrm{P}$ et al, conducted a study on one hundred fifteen patients and concluded that endometrial aspiration is a simple, safe, and effective method to sample 
endometrium in cases of AUB avoiding risk of anesthesia and is less time-consuming. In this study, heavy menstrual bleeding was the most common presentation of AUB. Adequate samples were obtained in $86 \%$ of cases while $13.9 \%$ of cases' sample was inadequate for opinion, many of which were later underwent hysteroscopy and/or dilatation and curettage (D and C) in operation theater. It was found that atrophic endometrium was the most common cause for inadequate sample. Out of them, uterine malignancy was diagnosed in three cases. ${ }^{13}$

\section{CONCLUSION}

Present study showed that endometrial aspiration biopsy is an outpatient procedure that can be performed without anaesthesia, analgesia, premedication and cervical dilatation. It preserves stromal architecture better and takes shorter time compared to dilatation and curettage. Hence it is an alternate to traditional dilatation and curettage in diagnosing endometrial pathologies in women with abnormal uterine bleeding. However, larger study with long term follow up is required to reach better conclusion.

Funding: No funding sources

Conflict of interest: None declared

Ethical approval: The study was approved by the Institutional Ethics Committee

\section{REFERENCES}

1. Fraser IS, Critchley HO, Broder M, Munro MG. The FIGO recommendations on terminologies and definitions for normal and abnormal uterine bleeding. Semin Reprod Med. 2011;29(5):383-90.

2. Cote I, Jacobs P, Cumming D. Work loss associated with increased menstrual loss in the United States. Obstet Gynecol. 2002;100:683-7.

3. Ghazi MA. Endometrial histo-pathological changes in women with abnormal uterine bleeding in Kirkuk City, a clinico-pathological study. Med J Babylon. 2013;10(3):1023.

4. Gayle M, Tarin A. Schmidt-Dalton, MD, Patrice M. Evaluation and management of abnormal uterine bleeding in premenopausal women. Am Fam Physician. 2012;85(1):35-43.
5. Rachamallu L, Bhavani V, Byna P. Histological correlation of Pipelle endometrial sampling with dilatation and curettage in abnormal uterine bleeding. Int J Reprod Contracept Obstet Gynaecol. 2015;4:1324-9.

6. Yasmin F, Farrukh R, Kamal F. Efficacy of Pipelle as a tool for endometrial biopsy. Biomedica. 2007;23:116-9.

7. Machado F, Mereno J, Carazo M, Leon J, Fiol G, Serna R. Accuracy of endometrial biopsy with the Cornier Pipelle for diagnosis of endometrial cancer and atypical hyperplasia. Eur J Gynaecol Oncol. 2003;24;279-81.

8. Huang GS, Gebb JS, Einstein MH, Shahabi S, Novetsky AP, Goldberg GL. Accuracy of preoperative endometrial sampling for the detection of high-grade endometrial tumors. AM J Obstet Gynaecol. 2007;196:1-5.

9. Patil P, Venigalla S, Lingaiah M, Kumar H, Raju K. A comparative evaluation of the three different methods of endometrial sampling in the diagnosis of perimenopausal bleeding. J Clin Gynaecol Obstet 2014;3(4):133-7.

10. Baral R, Pudasini S. Histopathological pattern of endometrial samples in abnormal uterine bleeding. J Path Nepal. 2011;1:13-6.

11. Jairajpuri ZS, Rana S, Jetley S. Atypical uterine bleeding-histopathological audit of endometrium. Al Ameen J Med Sci. 2013;6(1):21-8.

12. Shams G. Comparison of Pipelle de cornier with conventional dilatation and curettage in terms of patients' acceptability. J Postgrad Med Inst. 2012;26(4):214-7.

13. Singh P. Abnormal uterine bleeding-evaluation by endometrial aspiration. J Midlife Health. 2018;9(1):32.

Cite this article as: Tomar NS, Sandhu S, Mahipal S, Chaudhary A. A comparative study to evaluate endometrial aspiration using Karman's cannula versus dilatation and curettage in cases of abnormal uterine bleeding. Int J Reprod Contracept Obstet Gynecol 2020;9:1218-21. 